\title{
Tainted transfusion leaves Japan scrambling for safer blood tests
}

Even as the list of emerging pathogens continues to grow, governments are struggling to keep their blood supplies clear of the most pressing known threats. The latest scare comes from Japan, where health officials in December announced that a patient had become infected with HIV after receiving a blood transfusion.

"We were shocked," says Kazunari Tanaka, a spokesman for the Japanese health ministry's Blood and Blood Products Division. "We want to take blood safety to a higher level."

Although the donor's blood had tested negative for HIV in May 2003, the case was discovered when a more sensitive test in November revealed his blood is HIV-positive. In December, the recipient tested positive for an HIV strain identical to that found in the donor.

The current case is the first since a new, more sensitive, system-the nucleic acid test (NAT) — was put in place in 1999 as a second line of detection. Because the NAT amplifies viral DNA, it can detect small amounts of virus. Of the 315 samples that have tested positive for HIV since 2000, the NAT detected the virus in 8 samples that had cleared other tests. Although several other nations, including the US and many European countries, use the NAT to screen for HIV, Japan is the only country to use it to screen samples for both hepatitis B and C.

Despite the NAT's promise, a Japanese health ministry investigation reported last summer that blood tainted with HIV and other viruses might have slipped through the system. Soon after, Japan approved its first law regulating blood supply. In December, the ministry said that hepatitis C-infected blood drawn in 2000 had been given to at least one patient.

There is some question over whether such cases are underreported, but the recent case of $\mathrm{HIV}$ and one possible case of hepatitis $\mathrm{C}$ are the only ones in some 8 million transfusions over the last four years, maintains Tanaka. By comparison, the risk for HIV transmission through transfusion is 1 in 3 million in the US, and one in several thousand in China and Thailand.

Japan uses the NAT on a pool of 50 samples of donor blood; the US screens pools of 16 samples. If a batch tests positive, samples are tested individually, but the more samples pooled together, the less likely tests are to detect viruses.

Testing individual samples is ideal, "but both cost and logistics are problems for single-unit testing," says Harvey Klein, head of the Department of Transfusion Medicine at the US National Institutes of Health. Technologies being developed at the American Red Cross might solve these problems, he adds.

The Japanese Red Cross, which now manages

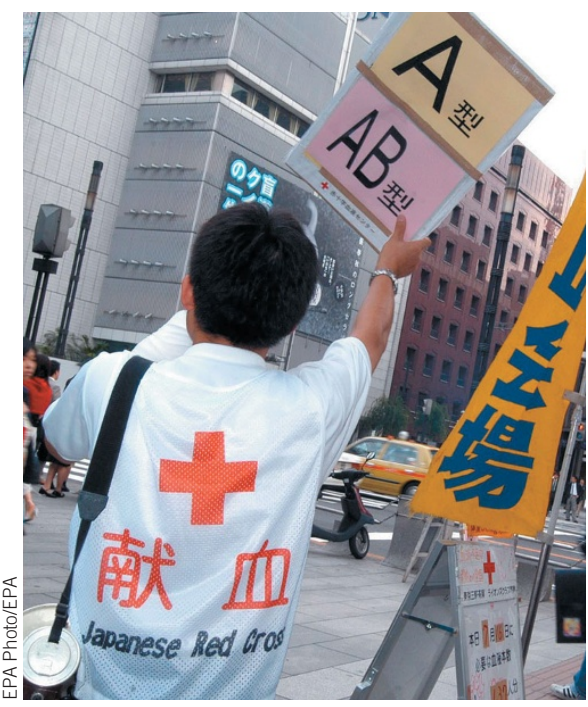

Japan's blood tests missed HIV in at least one case.

Japan's blood supply, insists that diluting samples by pooling only 20 samples would still not have picked up the virus-but it has not done those tests. Under orders from the health min-

istry, however, the organization plans to begin using 20-sample pools within six months.

The fact that every virus requires a different test makes comprehensive testing a costly proposition. Each new pathogen, such as the West Nile virus, adds to the burden, says Tanaka. The ideal solution, he says, would be to kill or maim pathogens in one fell swoop.

One promising alternative is adding chemicals such as amotosalen, which damages bacterial and viral DNA without harming red blood cells, platelets and plasma. The treatment, known as pathogen inactivation, would also be effective against emerging pathogens, but adding chemicals to blood could have unanticipated long-term effects. The method is already in use for platelets in Norway, but no adverse reactions have yet been seen.

Japan is especially anxious to find a comprehensive solution to the problem, as it is the only developed nation with a rising HIV infection rate (see page 215). Between 1987 and 2003, the proportion of donor samples testing positive for the virus shot up from $0.13 \%$ to $1.55 \%$.

David Cyranoski, Tokyo

\section{WHO defends malaria policies in Africa}

News about malaria rarely garners much interest outside the developing world. But in recent weeks, the World Health Organization (WHO) has had to publicly defend itself against scathing critique from international scholars, who claim the organization's malaria treatment policies in Africa are tantamount to "medical malpractice."

The WHO recommends that countries use artemisinin-based combination therapy (ACT) - derived from sweet wormwood-the gold-standard treatment for malaria. ACT is 10 times as expensive as the widely used chloroquine, but in most countries, resistance to chloroquine has rendered it virtually ineffective.

Led by UK expert Amir Attaran, the scholars charge that the WHO and the Global Fund to Fight AIDS, Tuberculosis and Malaria are funding Ethiopia, Kenya and other nations to treat millions with the conventional drugs, rather than with ACT. Although figures for child mortality in some regions have risen by as much as 11-fold, the scholars say, the organizations are providing insufficient training and assistance to those nations (Lancet 363, 237-240; 2004). Their criticisms echo earlier complaints from the group Medecins Sans Frontières.

The critique has put the WHO, which has recently spearheaded proactive initiatives to combat AIDS and other threats (Nat. Med. 10,

\section{2; 2004), under international scrutiny.}

"I don't think they're guilty of medical malpractice, but I do think they're guilty of incompetence," says Roger Bate, a visiting fellow at the American Enterprise Institute and director of the advocacy group Africa Fighting Malaria. "They're concentrating on AIDS because it's not something you can duck, but they're dropping the ball on other important issues."

Allan Schapira, coordinator of strategy and policy for the WHO's Roll Back Malaria, says the charges are "completely unfair." He notes that as countries' grants are evaluated over the five-year cycle, they will have to prove that they are switching to ACT. The WHO is also developing schemes to increase countries' access to ACT and improve their drug procurement strategies.

Still, Schapira admits that resistance to adopting the new treatment remains - even among some WHO ground-level representatives. In some cases, he adds, health ministers acknowledge the need but remain hesitant, in part due to skepticism about international funding.

"We need to acknowledge that we should have been much more insistent and firm in this message than we have been," Schapira says. "We have to say the same things we have said until now-but in a stronger voice."

Bruce Diamond, Fort Lauderdale 